Bull. Mater, Sci., Vol. 5, No.2, June 1983, pp. 123-126. (C) Printed in India.

\title{
Differential scanning calorimetric studies of polyester fabrics used in sewing ring of an heart valve
}

\author{
K SREENIVASAN, PRABHA D NAIR and V V BHUJLE \\ Laboratory for Technical Evaluation of Biomaterials, \\ Sree Chitra Tirunal Institute for Medical Sciences and Technology, \\ Satelmond Palace Campus, Poojapura, Trivandrum 695 012, India \\ MS received 31 December 1981
}

\begin{abstract}
Experimental values of heat of fusion for two indigenous polyester fabrics, candidate materials used in sewing ring of an heart valve, were 25.5 and $52.7 \mathrm{~J} / \mathrm{g}$ while it was $65.3 \mathrm{~J} / \mathrm{g}$ for an imported Dacron fabric The latter was selected as a reference material in view of its long clinical record. The implications of the observed differences in $T_{g}, T_{m}$ and per cent crystallinity are discussed and some level III test areas indicated.
\end{abstract}

Keywords. Polyester fabrics; heart valve; differential scanning calorimetry.

\section{Introduction}

The characteristics required of a material in cardiovascular application vary markedly with the particular application. Moreover, even where the ultimate functional requirements of a material can be specified, the imperfect state of our understanding of blood-material interactions at present makes it highly questionable that these functional requirements can be translated into values of physicochemical properties of the material. The Working Group on Standards for Physicochemical Characterisation of Biomaterials formed by the National Heart, Lung and Blood Institute, for instance, concludes that the development of performance standards for the materials at the present time would be inappropriate (NIH Publication No. 80-2186, 1980). Instead, it recommends the development of a compendium of appropriate test methods themselves. Following these guidelines we wished to explore the suitability of differential scanning calorimetry (DSC) as a test method for some of the materials used in devices currently being fabricated at this Institute. We present here the results of application of DSC for two of our candidate materials which were considered for fabricating sewing ring of an heart valve. A Dacron Fabric procured from United States Catheter and Instrument Incorporation served as a reference material in view of its long clinical record as a safe and satisfactory biomaterial.

\section{Experimental}

Prior IR spectroscopic studies confirmed that all the samples used in the present studies were chemically identical. The IR spectra were similar and identical to that of 
polyethylene terephthalate. Two indigenous polyester samples (2 to $5 \mathrm{mg}$ ) $(A)$ and $(G)$ and the imported Dacron Fabric $(I)$ were scanned using a Du Pont 990 Thermal Analyser with 910 DSC system as an accessory. Heating thermograms of samples were obtained in non-hermetic crimped pans in an atmosphere of air with a programmed heating rate of $10^{\circ} \mathrm{C} / \mathrm{min}$. To determine the heat of fusion, the instrument was calibrated using indium $(\Delta H=28.4 \mathrm{~J} / \mathrm{g})$. Time-base scannings were carried out with a programmed heating rate of $5^{\circ} \mathrm{C} / \mathrm{min}$ employing a time base of $0.5 \mathrm{~min} / \mathrm{cm}$. A starting temperature of $210^{\circ} \mathrm{C}$ was isothermally reached and the limit temperature was set at $290^{\circ} \mathrm{C}$. Two scans, using samples of different weights, for each sample were obtained. Heat of fusion $\Delta H$ was calculated using the relationship

$$
\Delta H=\frac{60 A B \Delta_{q s} E}{m}
$$

where $A$ is peak area $\left(\mathrm{cm}^{2}\right) B$ is time base setting $(\mathrm{min} / \mathrm{cm}), \Delta_{q s}$ is $Y$ axis sensitivity setting $(\mathrm{mV} / \mathrm{cm}), E$ is the cell calibration coefficient $(\mathrm{mW} / \mathrm{mV})$ and $m$ is the sample mass in $\mathrm{g}$. Per cent crystallinity for samples $(A)$ and $(G)$ was so computed (Gill and Levy 1974) as to correspond to an assumed $100 \%$ crystallinity value for sample $(I)$.

\section{Results and discussion}

As can be seen from table 1 the glass transition temperature $T_{g}$ is higher for the two candidate materials $(A)$ and $(G)$. Though it is generally implied that $T_{g}$ is a material constant for a given polymer the actual shape of the curve in the transition region is a complex function of specimen pre-treatment (and experimental conditions). $T_{g}$ being a linear function of $\log$ (cooling rate)(Richardson 1978) it serves as a processing variable. The differences observed in $T_{g}$ under identical experimental conditions such as those seen in the present case indicate different processing conditions. In their intended application steam sterilisation by autoclaving is recommended for the present materials. In this context it should be noted that whenever heat treatment exceeds $T_{g}$ it can induce morphological and surface changes

Table 1. Comparison of DSC results for the three samples.

\begin{tabular}{lcccc}
\hline & $\begin{array}{c}\text { Glass transi- } \\
\text { tion temperature } \\
T_{g}\left({ }^{\circ} \mathrm{C}\right)\end{array}$ & $\begin{array}{c}\text { Crystalline } \\
\text { melting point } \\
T_{m}\left({ }^{\circ} \mathrm{C}\right)\end{array}$ & $\begin{array}{c}\text { Heat of } \\
\text { fusion } \\
\mathrm{H}, \mathrm{J} / \mathrm{g}\end{array}$ & $\begin{array}{c}\text { Relative \% } \\
\text { crystallinity }\end{array}$ \\
\hline Dacron $(I)$ & $60 \pm 5$ & 260 & 65.3 & 100 \\
Polyester $(A)$ & $75 \pm 5$ & $246^{*}, 248$ & 25.5 & 39 \\
Polyester $(G)$ & $75 \pm 5$ & $250^{*}, 256$ & 52.7 & 81 \\
\hline
\end{tabular}




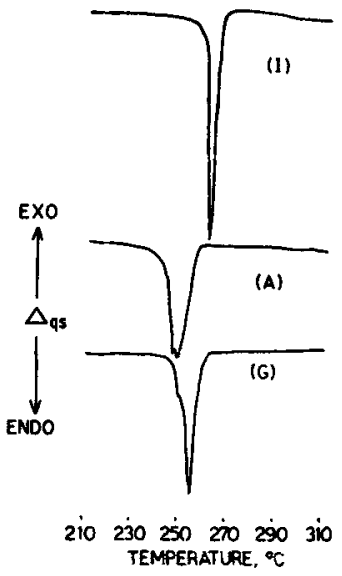

Figure 1. DSC curves for Dacron $(I)$ and two candidate materials $(A)$ and $(G)$.

in the system which might be of significance in blood-material interactions (Bruck 1974). As experimental studies of this nature do not exist at present the implications of the observed differences in $T_{g}$ for the three samples studied cannot be assessed at this stage. Its clarification would constitute that the Working Group calls a level III test. (Level III tests are those which are still in a developmental category and which represent directions for future development where further information on bulk properties appears necessary to explain or predict the performance of materials in devices).

Crystalline melting temperature, peak-widths and peak-shapes are different for the three samples (figure 1, table 1). Wider peaks observed for the two candidate materials imply wider distribution of crystallite sizes. The doublets observed are indicative of two crystalline regions or melting behaviour. These observed differences certainly indicate different thermal history or in other words different processing conditions. Again, in the context of presently observed differences in $\Delta H$ values it is to be noted that in a recent survey wide variations have been found in data of the experimental heat of fusion $\Delta H$ for polyethylene terephthalate which has been crystallised or annealed under varying conditions (Illers 1980). Illers has reported, under different annealing conditions, $\Delta H$ values ranging from $8 \mathrm{~J} / \mathrm{g}$ to $81.2 \mathrm{~J} / \mathrm{g}$.

Per cent crystallinity for sample $(G)$ is 81 while for sample $(A)$ it is only 39 . These values are only relative and correspond to an assumed $100 \%$ crystallinity for the sample $(I)$. Contrasting the crystalline regions with amorphous phase is nuite important in order to relate stability or resistance to change, either physical or chemical. The crystalline area exhibits a sharp melting point, a high density and a high modulus when compared to amorphous area of the same substance. Most pertinent, however, is the expectation that crystalline, region will resist solubilisation and should be far more difficult to penetrate with other molecules, such as oxygen, than the amorphous area (Conley 1970). Thus it could be expected that highly crystalline regions of polymer would be more resistant to both chemical deterioration and physical changes than the amorphous areas and this lends much significance to per cent crystallinity values. 


\section{Conclusion}

Differential scanning calorimetry can be effectively used in enforcing rigorous quality control protocols. Some of the sensitive parameters it presents are essentially the feed-back parameters needed at processing stages for obtaining tailor-made biomaterials. Better understanding of the significance of $T_{\boldsymbol{g}}$ and per cent crystallinity in biocompatibility and long range performance studies should form a future effort area (material-autopsy studies are being planned towards this goal). On the basis of the present studies, of the two candidate materials, the sample $(G)$ has been preferred for the intended application.

\section{References}

Bruck S D 1974 Blood compatibility of synthetic polymers - An introduction (Springfield: Charles C Thomas) p 113.

Conley R T 1970 in Thermal stability of polymers (ed) R T Conley (New York: Marcel Dekker) Vol I p. 6 Gill P S and Levy P F 1974 in Analytical calorimatry (eds) R S Porter and J F Johnson (New York: Plenum) Vol 3 p. 293.

lllers K H 1980 Colloid Polyn. Sci. 258117

NIH Publication No. 80-2186, 1980 Guidelines for Physico-chemical characterisation of biomaterials, Report of the National Ileart, Lung and Blood Institute Working Group, U.S. Department of Health and Human Services.

Richardson M J 1978 in Developments in polymer characterisation 1, (ed) J V Dawkins (London: Applied Science Publishers) p. 225 